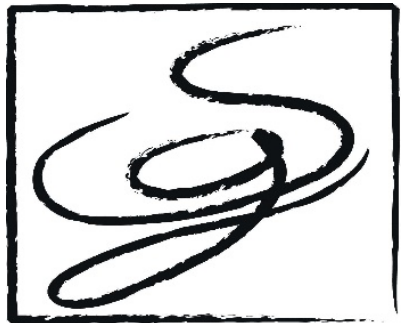

SEMINARIO DE INUESTIGACIÓN DE GÉNERO Y ESTUDIOS GULTURALES

\section{Un viaje espacial y temporal: las mujeres bajo el poder patriarcal y dictatorial en Eni Furtado no ha dejado de correr de Alicia Kozameh}

\begin{abstract}
A spatial and temporal journey: women under patriarchal and dictatorial power in Eni Furtado no ha dejado de correr by Alicia Kozameh
\end{abstract}

\section{Gaojie Lyu}

Universidad Carlos III de Madrid gaojie.lyu@alumnos.uc3m.es

Fecha de recepción: 2/06/2021 Fecha de evaluación: 19/07/2021
Fecha de aceptación: 15/11/2021

\title{
Resumen
}

En el presente trabajo se propone un análisis en torno al sufrimiento y la resistencia de las mujeres que buscan conseguir su propio espacio contra el poder patriarcal y dictatorial y sus consecuencias, a través de un viaje espacial y temporal que constituye Alicia Kozameh (Rosario, 1953) en su novela Eni Furtado no ha dejado de correr. A lo largo de este artículo, se pretende visualizar la búsqueda del espacio literario de la autora misma; el dolor causado por la represión patriarcal y dictatorial; ciertos espacios como representación del poder parental, y la lucha de las mujeres en contextos de violencia. Ese "correr", ese desplazamiento espacial y temporal que realizan las protagonistas -Eni escribiendo, Alcira volviendo a la Argentinaes lo que les permitirá articular lo indecible y el trauma. Eni Furtado no ha dejado de correr, que se publicó en 2013, es el sexto texto narrativo de la escritora argentina Alicia Kozameh. En la novela, a través de varios puntos de vista que abarcan múltiples perspectivas, se configura un hecho central: el abuso sexual de una niña de diez años. Debido a su propia experiencia como encarcelada durante la dictadura militar de Argentina, Alicia Kozameh se ha dedicado a escribir sobre temas relacionados con la prisión y el exilio en sus primeras obras. Esta novela, en concreto, se considera como uno de los ejemplos más representativos entre sus últimas novelas, puesto que se centra en el espacio privado de la familia y el abuso sexual de menores; simultáneamente, incorpora otro hilo que manifiesta la violencia política y el exilio de manera implícita, creando así una analogía entre la violencia dictatorial y la represión patriarcal que sufren las mujeres. Todo ello abre un horizonte más amplio para representar la violencia y el trauma dentro del universo literario de Kozameh. En definitiva, con este trabajo se espera aportar un punto de vista interesante, que contribuya a ampliar la reflexión en torno al género, el espacio y el poder. 
Palabras clave: Alicia Kozameh; poder patriarcal; espacio; mujeres; abuso sexual de menores; violencia; trauma

\begin{abstract}
Based on the spatial and temporal journey composed by Alicia kozame (Rosario, 1953) in her novel Eni Furtado no ha dejado de correr, this paper analyzes the suffering and resistance of women who seek to achieve their own space within the patriarchal and dictatorial power. Throughout this article, its purpose is to visualize the search for the literary space of the author herself; the spatial and temporal mobility of the two protagonists; the pain and trauma caused by patriarchal and dictatorial oppression; certain spaces as a representation of parental power, as well as the struggle of women in a violent environment. Eni Furtado no ha dejado de correr, which was published in 2013, is the sixth narrative work by the Argentine writer Alicia Kozameh. In this novel, through various points of view covering multiple perspectives, a central fact has been configured: the sexual abuse of a ten-year-old girl. Due to her own experience as a prisoner during the military dictatorship in Argentina, Alicia Kozameh dedicated herself to writing on issues related to prison and exile in her early works. This novel, in particular, is considered one of the very representative examples among his latest narrative novels, since it focuses on the private space of the family and the sexual abuse of minors; simultaneously, it incorporates another clue to express political violence and exile in an implicit way, thus establishing an analogy between dictatorial violence and the patriarchal oppression suffered by women. All of these have opened a broader vision to represent violence and trauma within Kozameh's literary universe. In short, through this work I hope to put forward a different point of view, which will contribute to the expansion of thinking on gender, space and power.
\end{abstract}

Key words: Alicia Kozameh; patriarchal power; space; women; sexual abuse of minors; violence; trauma

\title{
1. Introducción: el espacio literario de la escritora
}

Lo que me pasa así es que comprendo los hechos, los entiendo, los elaboro a través de las formas creativas. Es una obsesión la que tengo de entenderlo todo. Después de que el hecho sucedió, lo instalo en mi mente como ficción para que mi sistema digestivo se lo aguante, digamos, y salga como un producto diferente y nuevo (Kozameh, 1995: 95).

La escritora argentina Alicia Kozameh (Rosario, 1953) así explica su obsesión por la escritura durante una entrevista con Erna Pfeiffer. No resulta sorprendente que la autora tenga que lidiar con tantas dificultades y perplejidades frente a un mundo plagado de sufrimientos e inquietudes, debido tanto a la violencia familiar que sufrió durante la infancia como a la violencia política que experimentó en la última dictadura argentina. De esta manera, ella misma afirma que su escritura se concibe precisamente desde 
la vivencia del dolor: "La escritura es un viaje doloroso, es la experiencia de la vida" (Kozameh, 2009: 42).

Los primeros sentimientos del duelo que percibió Alicia Kozameh proceden de su familia desordenada, protagonizada por un padre banquero sumamente dominante, una madre sumisa y una hermana con discapacidad. La violencia física y verbal que los padres ejercían sobre Kozameh la condujo a buscar diferentes refugios desde muy pequeña, los cuales se podían construir solamente con un rincón posible, un cuaderno y un lápiz, tal y como ella afirma:

Aferrada a algunos elementos que representaban un refugio, aferrada a una tabla de salvación: primero algún rincón de la casa, más tarde en el último asiento en el salón de clase, después sentada en el umbral, en la vereda, siempre una lapicera, o varias, de colores, y siempre, casi desproporcionadamente siempre, un cuaderno (Kozameh, 2009: 43).

Sus propios espacios y el cuaderno en el que podía expresar sus perplejidades, reflexiones y tristezas constituyen un verdadero refugio bajo el poder patriarcal de la familia. Con el transcurso del tiempo, Kozameh intentó resistir a las restricciones que la familia le imponía y la opresión de los padres para hacer que cumpliera sus reglas. Finalmente, logró emanciparse escapando de la casa paterna a los diecisiete años. Y sus recuerdos infantiles se encuentran expresión en sus novelas, por ejemplo, en Patas de avestruz (2003) se narra pormenorizadamente el miedo de la protagonista, que se hace patente mediante la descripción de los gestos corporales de sus padres. Tales experiencias, al final, se convierten en una fuente de creación en la que una parte de la vida de la autora se incorpora a los personajes ficcionales, para revivirse y comprender sus preocupaciones y miedos infantiles.

Por otra parte, Kozameh fue detenida en 1975, poco antes del comienzo de la última dictadura argentina, del llamado "Proceso de Reorganización Nacional". Pasó tres años y tres meses como presa política en distintas cárceles argentinas: primero, en el sótano de la Alcaldía de Mujeres de la Jefatura de Policía de Rosario; luego, en la penitenciaría de Villa Devoto en Buenos Aires. Durante la reclusión, la dominaba una gran necesidad de escribir para superar tanto el dolor físico como el horror que se albergaba en su corazón. No obstante, la cárcel se erige como un espacio de imposibilidades en el que "la represión se apropiaba de o destruía cualquier elemento que estuviera en nuestras manos, que nos perteneciera, a su capricho" (Kozameh, 2009: 46). Kozameh y sus compañeras de prisión escribieron clandestinamente poemas y llevaron a cabo una serie de acciones contra las celadoras con el fin de salvar las producciones literarias que se realizaban en la cárcel.

Después de su amnistía en 1979, se exilió a los Estados Unidos, una tierra completamente desconocida. De acuerdo con Carlos Thiebaut, la experiencia del mal en los campos de concentración es totalmente incomprensible, ya que los crímenes han sobrepasado demasiado las facultades humanas de percepción, de imaginación y de juicio, incluso 
parece inadecuado describirlo como una mera infracción (Thiebaut, 2005: 21). En este sentido, con el fin de organizar los acontecimientos que sucedieron, superar el trauma psicológico y la nostalgia, e intentar comprender el mal que vivió, la forma a la que Kozameh recurre es la escritura, pero no sin dificultades, puesto que la narración de un trauma es siempre problemática y las palabras se hacen insuficientes ante el dolor físico y psicológico.

Por eso, en el agosto de 2004 Kozameh volvió al sótano de Rosario y la cárcel de Villa Devoto para preparar la escritura del cuento "Bosquejo de alturas". Tal y como lo que apunta Kozameh en su artículo "No hay pasado. Y otras convicciones", para materializar los detalles en la memoria y para obtener una visión panorámica de todo el grupo, debe renovarle la vida y dar cuenta ese estado físico y mental. Por este motivo, regresó a los lugares plagados de inquietudes, horrores y recuerdos, empezando así un viaje doloroso a Argentina. En los dos sitios recuperó de golpe la experiencia carcelaria. "Estaba allí otra vez, y caminaba por los pasillos, los pabellones y las celdas, el patio de Devoto [...] La situación produjo más de un shock. El shock de estar nuevamente inmersa en una realidad agobiante" (Kozameh, 2019: 259). Los espacios en los que experimentó la tortura y la amenaza de la muerte se han transformado ya en sitios de memoria, en edificios testimoniales para presentar ese abuso del poder. Los espacios físicos y concretos preservan la Historia del país en tanto la memoria personal que Kozameh piensa mantenerla siempre en viva.

Eni Furtado no ha dejado de correr (2013) es una novela muy representativa entre las obras publicadas por Kozameh durante los últimos años, porque abarca todos los terrenos de una sociedad destruida por abusos tanto por parte del poder dictatorial como del patriarcado. Cuenta con treinta y tres pasajes, marcados únicamente por asteriscos, sin numeración de capítulos, en los que se incluyen distintos modos de expresión, tales como diálogos, fragmentos de un cuaderno, recuerdos, monólogos y cartas. Las múltiples perspectivas de los distintos personajes, al final, convergen en un mismo hecho del pasado de hace casi cuarenta años: el abuso sexual que Eni sufrió por parte del padre de una amiga de su infancia, lo cual representa el antecedente de una vida plagada de dolor, pobreza y obstáculos.

Con sus tácticas literarias complejas y sútiles, Kozameh crea en esta novela un espacio donde se entremezclan lo real y lo ficcional, lo temporal y lo geográfico, lo natural y lo humano. Tal y como Pfeiffer comenta sobre la escritura de Kozameh:

Seremos testigos y cómplices de vertiginosas acrobacias de la palabra escrita, rayanas en saltos (in)mortales, bailes frenéticos, atrevidos actos de equilibrio y jocundos juegos malabares, siempre que sepamos apreciar y disfrutar el continuo descubrimiento de nuevas formas experimentales, sin precedentes (Pfeiffer, 2013: 13).

Se les muestra a los lectores en la novela una escena en la que confluyen los hilos temporales y los recuerdos que habían sido enterrados por Eni Furtado. Cada transfiguración cartográfica marca un viraje crucial 
para las protagonistas. A través del viaje entre el presente y el pasado, se van configurando paulatinamente los sufrimientos que experimentaron las mujeres bajo ese poder patriarcal y dictatorial.

Así pues, las vivencias dolorosas de la propia Kozameh desembocan en una profunda empatía ante el sufrimiento de las demás mujeres, de modo que su literatura se compromete: "con la escritura, si la hemos vivido, de una manera y otra, como una imposibilidad. Con la memoria histórica, si la hemos visto amenazada" (Kozameh, 2009: 46). Por ende, su escritura se convierte en un arma y un espacio de denuncia ante las violaciones de los derechos humanos, en la que se hacen visibles la detención arbitraria, la reclusión, la práctica de la tortura, la represión dictatorial, el exilio, la violencia sexual y la dura supervivencia de las mujeres.

\section{De EE.UU. a Argentina: en busca del pasado}

- ¿Y de mi padre también te acordás?

-Sí. Claro.

-¿Te puedo preguntar algo?

-Dale.

- ¿Fue violento? Quiero decir: alguna vez, de alguna forma, ¿te provocó dolor? (Kozameh, 2013: 57).

Esta cita reproduce la primera vez que Alcira menciona el misterio que rodea a Eni, y la pregunta que se plantea es si Julio, el padre de Alcira, había abusado sexualmente a la pequeña Eni, cuando esta vivía con ellos. Aunque han pasado cuarenta años, Alcira todavía intenta averiguar la razón por la que su amiga desapareció de repente de su familia y qué ocurrió entre su padre y ella, ya que la ansiedad de saberlo persigue a Alcira a lo largo de los años que transcurren desde la despedida. La atormentan numerosas dudas sin respuestas, que se ciernen sobre ella como "una nube, la perplejidad por acumulación de preguntas es una nube mayor, y la perplejidad por la falta de respuestas a tanta pregunta es una tempestad ingrávida y en lento, refrenado, inmóvil desplazamiento" (Kozameh, 2013: 102). Por lo tanto, si bien había perdido todo contacto con Eni a partir del día en que desapareció de su casa, y a pesar de la distancia espacial y temporal que las separa, Alcira volvió a buscarla desde Norteamérica.

Cabe subrayar que en esta novela, el tema del exilio de la joven argentina como presa política nunca se describe de manera explícita. Sin embargo, a través del proceso de búsqueda de su antigua amiga, se puede vislumbrar con claridad no solo la condición de exilio de la muchacha, sino también el panorama general de la sociedad postdictatorial de Argentina. Por ejemplo, a través de su monólogo, se insinúa que este proceso debe realizarse a distancia, desde un lugar ajeno a Argentina:

Desde el sur de Califonia, desde las costas del Pacífico, en las que la arena, las algas y el ánimo se mezclan y se frotan contra la orilla hasta confundir o clarificar, todo lo que podía percibir era que la búsqueda iba a ser una ocupación muy silenciosa, diría que secreta, a corto o a largo plazo, de acuerdo a las 
reales posibilidades que me otorgara la distancia (Kozameh, 2013: 65).

Evidentemente, la búsqueda desde el exilio es difícil y compleja, pero durante ese proceso Alcira descubre que, en la época postdictatorial, buscar a alguien desaparecido se ha convertido en un negocio en Argentina. En el diario y en varios sitios web especializados, pueden hallarse ciertos anuncios que ofrecen servicios para buscar a las personas desaparecidas. "Sea moderno: busque a alguien" (Kozameh, 2013: 103), porque el pueblo argentino había sufrido demasiadas pérdidas de aquellos seres queridos y la violencia del Estado durante la dictadura militar.

La palabra "desaparecido" se puede vincular directamente con la dictadura Argentina de 1976, puesto que la desaparición sistemática de personas fue uno de sus principales mecanismos para generar el terror entre el pueblo, hasta el punto de dominarlo completamente. En 1979 el dictador Jorge Rafael Videla presentó tal mecanismo en una entrevista que con el tiempo transcurrido parece tristemente ridículo: "Frente al desaparecido en tanto esté como tal, es una incógnita, mientras sea desaparecido no puede tener tratamiento especial, porque no tiene entidad. No está muerto o vivo [...] Está desaparecido1" (Adamoli, 2010: 30). En la novela, tras su estancia en prisión, Alcira logra abandonar su país natal. Es cierto que ha sido víctima del poder dictatorial, pero conserva la vida, mientras que muchas de sus compañeras siguen estando "desaparecidos". Fueron asesinadas y sus cuerpos no se van a encontrar nunca.

Entonces cabe preguntarse si el país natal realmente está lejos. La respuesta podría ser que no, porque si bien Estados Unidos y Argentina están separados por miles de kilómetros, solamente haría falta coger un avión para borrarlos. En cambio, para Alcira, estas dos realidades son completamente diferentes, puesto que volver a su patria y enfrentarse al pasado traumático implican revivir el dolor, re-experimentar la represión del poder dictatorial. Argentina simboliza para ella todo aquello de lo que ha buscado huir, un espacio lleno de violencia y terror, que ha ejercido un gran abuso sobre ella, hasta el punto de obligarla a escapar, emigrar, a quedar despojada de su patria. La vuelta al pasado se complica, porque ella ya no pertenece a ese lugar.

Por otra parte, lo que Alcira está buscando en el pasado, un lugar o un momento que no se puede definir, podría ayudarla en el presente. Es innegable que el deseo de desentrañar el enigma de Eni es el motivo principal de su regreso a Argentina, en la medida en que se ha convertido en una obsesión. Tal obsesión de perseguir la verdad constituye un "nolugar" del exilio, cuya característica esencial es la ausencia. En este sentido, se refiere a la falta de permanencia, la carencia de recuerdos, la ausencia de evocación hacia ellos y la imposibilidad de poderlos narrar (Gallardo, 2012: 14). Alexis Nouss explica que la noción de "no-lugar" no implica lo contrario de la idea de lugar, sino que la completa (Nouselovici,

\footnotetext{
${ }^{1}$ Los desaparecidos, como afirma el dictador, no tienen identidad, es decir, son personas que no existen, por ello, la protagonista insiste en encontrar a su amiga perdida y descubrir qué fue lo que la hizo desaparecer. Alcira quiere devolver a Eni la identidad que su padre le había arrebatado en el pasado.
} 
2014). Argentina es el lugar que Alcira se vio forzada a abandonar, de la misma forma, la ausencia de recuerdos sobre el abuso sexual que sufrió Eni es el "no-lugar" del que no se puede salir ni ir más allá física y mentalmente. Por lo tanto, bajo la necesidad de construirse de nuevo en el exilio, de alcanzar la dimensión incógnita de la memoria y de poder narrarla, Alcira decide volver a los lugares en los que ella y su amiga vivieron durante la infancia, y así regresa al tiempo pasado.

En el monólogo de Alcira, se manifiesta su propia actitud frente a la vieja herida:

¿Te liberaste de tu circunstancia? Las estrategias que instrumentamos para emanciparnos, ¿equivalen a una liberación? Yo sé que sabés bien que no. La única independencia sucede en la constante lucha por lograrla. Uno se salva en la lucha, a uno lo salva el traqueteo de la lucha (Kozameh, 2013: 65).

Por consiguiente, a pesar del trauma psicológico, siempre cuenta con la valentía de mirar atrás, de revivir el dolor para buscar lo que quiere. Alcira insiste en que no es la huida sino la lucha lo que abre una posibilidad de liberación. La emancipación es solo posible a través de la resistencia, del "traqueteo de la lucha". La pasividad es inútil en condiciones de violencia y peligro, porque solo la resistencia abre una vía para lograr una vida libre.

Las conversaciones entre las dos protagonistas se producen a través del teléfono. Por fin, Alcira logra encontrar a su amiga de la infancia, por lo que tiene la posibilidad de resolver las dudas que permanecieron en su corazón durante tantos años, sin darse cuenta de que sus investigaciones han causado cierto malestar para Eni. En este sentido, su interrogativo implica otro tipo de poder abusivo, porque la interlocutora de Alcira prefiere enterrar el trauma. Eni no quiere enfrentarse a ese pasado, ni revivir la situación de dolor, vergüenza y exclusión, que le tocó vivir en aquel entonces. La insistencia de Alcira ha dado lugar a un efecto negativo sobre Eni, quien se siente agredida por el interrogatorio al cual la somete su antigua amiga.

\section{De Laboulaye a Pergamino: el acontecimiento y el presente}

"Vos sabés: un día, ipaf!, después de casi cuarenta años, y cuando yo tenía todo resuelto, bien guardadito y enterrado, se me presenta tu hermana por teléfono desde Norteamérica. ¿Para qué? Para joder" (Kozameh, 2013: 297). Estas palabras forman parte del monólogo de Eni dirigido a la hermana de Alcira, quien murió hace muchos años. En esta breve cita se evidencia el motivo por el cual Eni responde negativamente a la llamada de Alcira.

La razón por la que Eni vivía con la familia de Alcira cuando aún no había cumplido diez años, es la muerte de su padre y la incapacidad de su madre para mantener a sus siete hijos. Eni y su madre precisamente son representaciones de aquellas mujeres de las clases bajas argentinas, cuya vida está sumida en la pobreza, y caracterizada por embarazos múltiples y duros trabajos domésticos. Por el contrario, dado que el padre de Alcira es 
gerente del banco, su familia pertenece a la clase media en la sociedad argentina de aquella época. Por lo tanto, cuando la familia de Alcira debía irse de Laboulaye por el trabajo del padre, la madre de Eni manda a su hija a vivir con la familia de su amiga.

Así pues, Eni se marcha con la familia de Alcira, primero, de Laboulaye a Rojas, posteriormente, de Rojas a Pergamino, lugares que la alejan tanto de su pueblo natal como de su familia de origen. Los desplazamientos geográficos, a la vez, comportan un total aislamiento psicológico y emocional para Eni, lo cual implica que ella se encuentra en una condición donde los miembros de su propia familia no le proporcionan ninguna protección ante la violación sexual del padre de Alcira. Tal y como Judith Herman apunta en Trauma y recuperación, en una situación de terror, las víctimas buscan espontáneamente su primera fuente de bienestar y protección. Los soldados cuya vida se encuentra en peligro de muerte, y las mujeres que sufren una violación imploran ayuda a sus madres o a Dios, pero cuando este grito queda sin respuesta, las personas traumatizadas se sienten absolutamente abandonadas, experimentando un hundimiento de la confianza básica (Herman, 1997: 92). Por lo que, en realidad, Eni sufre doblemente en este contexto: por una parte, la violación sexual ejercida por el padre de Alcira; por otra parte, dicha situación de aislamiento emocional.

El abuso sexual del padre de Alcira ha causado un profundo trauma tanto físico como psicológico para Eni. De acuerdo con Herman, la niña violada podría volverse a plantear los conflictos de desarrollo en la infancia y adolescencia que hacía tiempo que se habían resuelto, es decir, el trauma la obliga a revivir todas sus luchas anteriores por obtener la autonomía, y desarrollar su propia iniciativa, competencia, identidad e intimidad (Herman, 1997: 93). Sin embargo, el miedo podría reaparecer una y otra vez en el presente mucho tiempo después de que haya pasado el peligro. Por ello, resulta difícil retomar la cotidianidad, porque el trauma la interrumpe constantemente (Herman, 1997: 69). Durante muchos años, para Eni el sexo "siempre había sido una cosa tabú. [...] No había nada más sucio que el sexo" (Kozameh, 2013: 120). A lo largo de toda la vida, con una identidad destruida por la violencia sexual, Eni hace lo que puede para intentar sobrellevar la herida del abuso y para escaparse de la sombra del miedo:

Tantos años que me pasé haciendo las cosas lo mejor que podía [...] para poder decir: bueno, ahora cumplí, ya está, y aunque tenga que seguir trabajando, limpiando casas ajenas, valió la pena y por lo menos tengo algo de paz. Tantos años que esperé para eso y, ahora que está a punto de pasar, porque los dos chicos terminaron la secundaria, ahí, justo, justitojustito, me cae tu hermana a joderme la vida. Y ¿sabé qué? Yo no lo veo justo (Kozameh, 2013: 297).

Además, el acontecimiento viola la autonomía de la persona en el plano de la integridad corporal básica (Herman, 1997: 93). El cuerpo de la pequeña Eni se convierte en el espacio donde se articula el abuso de un orden político que vuelve invisible la violencia sobre los cuerpos más 
vulnerables para exhibir la ficción de la invulnerabilidad masculina y patriarcal (Forcinito, 2019: 63). Ese cuerpo invadido, dañado y fracturado es como un espejo en el que se refleja de manera explícita la ruptura de la integridad de la personalidad, por lo que Eni cuestiona reiteradamente su propio cuerpo y su identidad:

Me miraba las manos y pensaba: ¿Qué hago ahora con estas manos? Y con estas piernas. ¿Para qué me sirve este cuerpo? ¿De quién es, me pregunto, este cuerpo que tengo? ¿Por qué algo puede llegar de cualquier lado y desparramarle a uno la sangre por aquí y por allá, como si ese algo fuese el dueño de mi cabeza y de mis piernas y de mi cerebro? ¿Uno no es de uno mismo, yo pensaba? ¿De quién es uno? (Kozameh, 2013: 12).

A pesar del tiempo transcurrido, la repugnancia que el padre de Alcira ha causado en su cuerpo no la abandona nunca a lo largo de su vida, de manera que Eni no puede superar el desprecio que el padre de su amiga le ha generado, violando no solo su cuerpo, sino también su autonomía y dignidad:

¿Qué me puede quedar, después de cuarenta y pico años? Bueno, digo, además del asco. [...] ¿A vos no te parece que con todas las veces que me habré bañado en casi cincuenta años, con tanta inundación que uno sufrió, con tantos cambios, con tantas pérdidas, imagínate, me habrá quedado algo? Y como todo lo que sale de adentro del cuerpo cada vez que una tiene un hijo, ¿no se me habrá lavado lo suficiente todo ese lugar del cuerpo? (Kozameh, 2013: 277-279).

Julio, el padre de Alcira, quien posee el poder absoluto en su núcleo familiar, se aprovecha de su condición de cabeza de familia para ejercer un dominio sobre quienes están dentro de su hogar. Establece en su casa un verdadero sistema dictatorial machista dominado por la violencia, el miedo y el silencio. Él no solo forma parte del sistema represivo, sino que intenta fortalecer su poder dentro del espacio privado. "Está en todos lado, en puro metido" en la familia (Kozameh, 2013: 263). Cuando la escena de la violación es descubierta por Ruth, la madre de Alcira, Julio echa toda la culpa a la niña, al mismo tiempo, amenaza a su mujer con el propósito de intimidarla: "Si ponés un pie fuera de esta casa, no sólo no volvés a entrar, sino que olvidate de recibir un centavo. Te denuncio a la Justicia por abandono de hogar y te jodés en serio" (Kozameh, 2013: 61).

A través de lo que menciona Julio, se puede deducir que, efectivamente la represión ejercida hacia las mujeres ha alcanzado todas las esferas de la sociedad. Ruth está sometida al poder patriarcal, hasta el punto de convertirse en cómplice del sistema machista, debido a la intimidación que se instaura tanto desde el espacio privado como desde el público. Ella insiste en que la culpable del acto es Eni, por lo que la insulta constantemente con las siguientes expresiones de menosprecio: "prostituta barata", "asquerosa", "atorranta". En este sentido, la madre no es capaz de empatizar con la niña, sino al contrario ella misma ejerce un poder sobre la muchacha, despreciándola y denigrándola, porque es incapaz de ver la 
culpa en el hombre que tiene a su lado. De acuerdo con Semilla Durán, las identificaciones de género no bastan para construir solidaridades entre las mujeres; la brecha del estatus social, y las diferencias de clase de educación y de religión atraviesan y desarticulan el colectivo femenino. Cuando todas las contradicciones se manifiestan, la construcción discursiva de los hechos gira en torno al rechazo hacia la víctima más vulnerable (Durán, 2019: 223), razón por la que Julio y Ruth se alían para inculpar a Eni, ya que ella es el eslabón más vulnerable de toda esa familia desestructurada y perversa.

Después de ese acontecimiento, Eni es encerrada en el dormitorio por la señora Ruth para evitar las "porquerías", lo cual, en cierto sentido, constituye otro nivel de aislamiento, ya que se le impide el intercambio con las fuentes de información exterior, la ayuda material y emocional. Además, la culpabilización ejercida por los padres provoca cierto sentimiento de vergüenza y duda en la pequeña Eni.

Herman afirma que la vergüenza se configura como una respuesta al quebrantamiento de la integridad física y la indignidad sufrida a ojos de otra persona. La duda se refleja en la incapacidad de mantener un punto de vista propio mientras se está vinculando a otros (Herman, 1997: 94). Por lo tanto, el encarcelamiento en el hogar para Eni supone no solo la pérdida de la libertad física, sino también el arrebatamiento del control de su capacidad de expresarse, es decir, los jefes de la familia la privan de la posibilidad de contar su trauma, sentimientos y pensamientos. Por un lado, la reclusión física le impide difundir el "escándalo", y por otro, la vergüenza que ella misma siente implica una reclusión voluntaria, por la que permanece callada dentro del dormitorio cuando la pequeña Alcira toca la puerta. En el cuaderno que redacta cuarenta años después, Eni le explica a Alcira: "Si abría la boca y te decía que estaba ahí, tenía que explicarte lo que había pasado y a eso sí que no lo podía hacer [...] cada vez que no entendías por qué esto o por qué lo otro, armabas unos escándalos increíbles" (Kozameh, 2013: 121).

Después de unas semanas de encierro en el hogar, los padres llevan a Eni a un colegio religioso, en el cual las monjas también le echan la culpa de todo, la aíslan y la tratan como si hubiera sido una especie de pecadora empedernida o una atroz delincuente juvenil. Por ello, no hay ningún refugio para Eni en el que ella pueda sentirse segura ni tratar de expresar todo aquello que le ha ocurrido, para intentar sanar la herida. Sufre una carencia afectiva tanto en el espacio privado como en el público. El hogar se ha convertido en una verdadera cárcel para las mujeres y niñas bajo el control del poder parental, en el que la violación y el cautiverio doméstico suelen pasar invisibles, porque ocurren en el interior de un espacio infranqueable, de un espacio estereotipado como seguro, propio e íntimo, caracterización que claramente se quiebra y destroza en esta novela. La escuela de las monjas, a su vez, representa la comunidad pública convencional, que promueve una actitud de compasión y sumisión ante el violador, sobre todo cuando este pertenece a un estatus superior al de la víctima, por edad, poder adquisitivo y condición socioeconómica. De manera que no solo el hogar es un espacio de agresión, sino que también lo es la esfera pública, 
en la que se obliga a la víctima a callar sus lamentos y a adoptar una actitud de resignación ante los abusos de los considerados "superiores" en la escala social.

En realidad, en la familia de Alcira, nunca se instaura un espacio que pertenezca a Eni, porque ella es un "otro" en ese hogar; no es de la familia plenamente, sino una niña acogida que sueña con poder tener un lugar propio. Tanto su madre como ella, habían pensado que podía vivir una vida mejor en la familia de Alcira. Tal y como la madre le dijo: "Vos perdiste a tu papá, aunque desde el cielo te ve y te habla, pero Alcira tiene uno, y si vivís con ellos vas a tener un papá postizo. Una familia completa" (Kozameh, 2013: 211). Pero, en realidad, Eni desde siempre se encuentra en una condición subordinada dentro de esa familia. Ese "papá postizo" marcará para siempre la vida y el carácter de su "hija postiza", a quien priva de poder desarrollarse con normalidad en su vida adolescente y también adulta. Esa vida mejor, esa "familia completa" que la madre le promete a su hija no existe para Eni.

El hogar para el hombre se muestra como un castillo, al contrario, para la mujer, sobre todo para una niña que no ha cumplido diez años, las barreras de la familia son poderosas e inadvertidas, por lo que no pueden ser superadas. Las mujeres suelen ser forzadas a someterse al hombre por su presunta inferioridad y dependencia económica, social, psicológica y legal, así como física, es decir, la mujer se construye socialmente como un ser subordinado que ha de aguantar con sumisión y paciencia todas las barbaridades con las que el mundo machista la atormenta. En la obra en concreto, la brecha de estatus sociales entre Eni y Julio, y la situación subalterna de la niña dan lugar a esta tragedia: una violación silenciada y un trauma causado por la culpabilización y la reclusión de una muchacha joven, cuya vida queda marcada para siempre no solo en el terreno de lo sexual, sino también en el de las relaciones interpersonales. Eni siente una gran pérdida tras ese abuso sexual: "Uno enseguida hace cuentas de lo que perdió en el camino. [...] Perdí una familia. No sería mi familia, pero la verdad es que sí lo era. O por lo menos yo lo sentía así" (Kozameh, 2013: 112).

A pesar del abuso del sistema represivo patriarcal, Eni Furtado "nunca ha dejado de correr" para conseguir su propio espacio, tanto en la familia como en la sociedad. Se escapa de su primer marido, un hombre machista, borracho y violento, y crece a sus seis hijos solo con sus propias fuerzas. Asimismo, trabaja de comadre y limpiando casas, hasta lograr comprar una "casilla" con sus propios ahorros; luego, trabaja en un hotel frecuentado por militantes, entre los cuales algunos incluso la tratan con respeto Ilamándola "señora". Por otra parte, de adulta Eni llega a la deconstrucción de los mecanismos de poder que se erigen en torno a ella mediante su reflexión autónoma, así ella se cuestiona a obediencia ciega de los subalternos: "¿Por qué a veces uno espera que ellos digan lo que hay que hacer? ¿Por qué todos creemos que ellos son los que deben cuidar a toda una familia o a todo un país, o a todo el mundo?" (Kozameh, 2013: 137). Todos los poderes, los militantes, los padres, los esposos, los superiores jerárquicos plantean estrategias de seducción para que toda la 
gente les obedezca, para lograr su supuesto derecho al abuso (Durán, 2019: 223).

Finalmente, tras tantos años de silencio y represión, Eni muestra una actitud de rechazo frente a la provocación de Alcira, quien, con sus preguntas, consigue abrirle viejas heridas que surgieron cuando era una niña y que la persiguen a lo largo del resto de su vida. Reviviendo una experiencia traumática, la víctima se arriesga a sufrir más daños, por lo que las personas traumatizadas se afanan por evitarlo (Herman, 1997:76). En este sentido, para Eni la llamada imprevista de Alcira supone un verdadero problema en el que se ve forzada a involucrarse, tal y como Eni lo considera: “¿Para qué? Para joder”.

\section{El cuaderno y la chiquita: el espacio literario}

Eni Furtado no ha dejado de correr también se distingue por su complejo tratamiento de la comunicación entre los cuatro personajes principales: Eni, Alcira, Julio y Ruth, dado que cada uno de ellos emite su mensaje en relación con la violación desde su propio punto de vista, a través de la primera persona, hablando o escribiendo. De esta forma, aparecen diversos hablantes con sus propias características, por ejemplo, el machismo en el lenguaje de Julio o el rencor en el monólogo de Ruth. Así, la autora configura todo un elenco de voces que tratan un mismo tema, sobre el que tanto tiempo han tenido que callar.

Erna Pfeiffer afirma que: "desde el mismo principio de la novela se va desplegando un amplio abanico de formas de tratamiento y situaciones comunicativas entre los distintos personajes, que lleva a constelaciones poco convencionales" (Pfeiffer, 2019: 76). La narración, desde múltiples perspectivas, ofrece cierta información contradictoria, porque contar la vivencia siempre implica hacerlo desde una experiencia e interpretación concretas. Por esta multiplicidad los lectores, junto con Alcira, avanzan en la búsqueda de la verdad acercándose a resolver ese enigma de la infancia de las protagonistas. El caso de Eni es aún más interesante, ya que su voz se emite desde dos herramientas, es decir, por una parte, se puede leer su cuaderno, escrito en forma de carta, y por otra parte se escucha su voz silenciosa mediante el monólogo dirigido a la hermana de Alcira.

En primer lugar, la novela se inicia con unas palabras escritas dirigidas a alguien, que se desconoce, en primera persona, similar a un estilo epistolar y también cuenta con ciertos rasgos de diario íntimo, testimonio o memoria (Pfeiffer, 2019: 78). En el segundo párrafo de la novela, se descubre con nitidez que lo que se reproduce desde el principio es el contenido de un "cuadernito", "Vos me plantaste frente a este cuadernito [...] Lo único: no me andés preguntando cuánto escribí. Si me apurás un poco no te escribo nada, y chau" (Kozameh, 2013:11). Entonces es posible comprender que el lector va a enfrentarse a un texto íntimo en el cual se podrían encontrar recuerdos, miedos y secretos de una voz. "Pero todo: los recuerdos, los miedos, la locura que una tiene, y la locura que a una le falta [...] Mirá, mirá las cosas que me hacés pensar, vos, con las ideas que me tirás para lograr meterme en este lío" (Kozameh, 2013:1112). 
Si bien se producen varios encuentros entre Alcira y Eni, de manera presencial o telefónica, esta última no quiere revivir su experiencia traumática, por lo que se niega a hablar de ella. Entonces, Alcira le pide que escriba lo que sucedió y que le mande el texto a Norteamérica. Finalmente, Eni logra reconstruir y reordenar sus recuerdos para transcribirlos en un cuaderno, el que se transforma en un espacio simbólico y literario, donde la historia personal de Eni se narra de forma fragmentaria ${ }^{2}$, insertándose en él algunos cuentos infantiles, memorias sobre los padres de Alcira y de ella misma, historias sobre sus propios hijos y trabajos. Parece que lo que escribe ha dejado de ser para Alcira y, en cambio, se convierte en un recorrido retrospectivo de su propia vida, o sea, una escritura personal que se dirige a la propia escritora. Esta actividad en algún grado implica una terapia para poder liberarse de una vez, a través de la resistencia y las palabras, del trauma que sufrió Eni en la infancia y que posteriormente la ha perseguido durante el resto de su vida.

$Y$ es precisamente en ese texto donde Eni por fin consigue su propio espacio, que le permite reflexionar y materializar sus pensamientos, sin miedo a ser reprendida ni culpabilizada por pensar, sentir o decir. Gracias a la escritura en el cuaderno, la Eni adulta regresa su mirada a la niña que dejó la infancia y la inocencia abruptamente, obligada por un "padre postizo", violada, agredida y, finalmente, aislada. Además, el hecho de poder escribir tranquilamente, en una habitación propia, tomando sus tiempos de ocio, representa una verdadera libertad:

Así que ya está. Y ya es más del mediodía, y a las tres de la tarde tengo que estar trabajando. Y antes voy a preparar la comida para que esté lista antes de que lleguen los muchachos y Omar, que vuelven todos casi a la misma hora. Y por supuesto que vuelven todos muertos de hambre. Así que ahora ya me levanto. Y te dejo (Kozameh, 2013: 308).

A pesar de los trabajos domésticos, finalmente consigue tiempo y espacio para escribir, para hacer lo que ella quiere, lo que hace que se sienta feliz y segura.

En segundo lugar, se encuentran unos monólogos dirigidos a un personaje llamado "la chiquita", en los que Eni constituye otro espacio para contar sus secretos y pensamientos tenebrosos, los cuales nunca aparecen en el cuaderno. "De todo esto, silencio. De esto no se entera Alcirita ni absolutamente nadie" (Kozameh, 2013: 30). Por lo tanto, se trata de un espacio, aún más íntimo que el del cuaderno, donde se expresa lo que se decide callar a los demás.

Esta chiquita a la que se dirigen las palabras secretas de Eni es la hermana de Alcira, una niña que era discapacitada física y mental, muerta años atrás, como se ha mencionado anteriormente, quien nunca tuvo la

\footnotetext{
${ }^{2}$ La historia de Eni no se narra tradicionalmente de manera lineal en el cuaderno, sino se constituye a partir de pedazos de los recuerdos. El resquebrajamiento de la unidad de la escritura, o sea, la estética fragmentaria empleada por Kozameh representa una fragmentación psicológica del personaje. Se trata de un símbolo de la ruptura de la integridad del cuerpo y de la identidad de Eni, causada por ese abuso sexual del padre de Alcira.
} 
capacidad de expresarse verbalmente ni de comprender lo que la gente le comunicaba. $Y$ es este hecho lo que la convierte en la confidente perfecta, alguien que nunca contará nada, ni tampoco juzgará a su interlocutora. La chiquita nunca podría haberse dado cuenta de la violación producida en su propia casa a causa de su enfermedad. Pero ahora, cuarenta años después, es transformada por Eni en la testigo de su dolor y oyente de sus ideas silenciadas. Confiesa a la chiquita muerta lo que no quiere compartir con Alcira, a la vez, cuestiona su búsqueda: "¿qué va a encontrar? Y lo otro: ¿dónde va a buscar para encontrar? Porque la verdad-verdad es que hay cosas que son de cada uno. Yo no le puedo dar a ella lo que quiere, porque es mío" (Kozameh, 2013: 277). El silencio de Eni pone de relieve el poder del sujeto narrativo, es decir, su capacidad de elegir a la persona que va a escuchar sus palabras y pensamientos. Estos monólogos se transforman para Eni en un espacio de resistencia, donde se colocan sus reflexiones incontables y se manifiesta su autonomía espiritual.

En contraste con el monólogo poético y lírico de Alcira, el texto escrito por Eni está lleno de expresiones orales y coloquiales con palabras como: "Bueno..." "imaginate" "nena" "¿eh?" "fijate", entre otras. Por una parte, los verba dicendi, según Erna Pfeiffer, tienen una importante función para mantener vivo el contacto entre emisora y receptora, destacando el elemento dialógico entre las coprotagonistas, la intencionalidad y la intensidad de su comunicación. La expresión escrita con características orales constituye un estilo típico de la comunicación directa y hablada. La cual, por otra parte, muestra también que Eni pertenece a las clases bajas, porque transgrede las leyes de la burguesía de mantener ciertas distancias en su manera de relacionarse con otros (Pfeiffer, 2019: 80).

Además, cabe subrayar el empleo de palabras "vulgares" en los pasajes dirigidos a la chiquita, porque es su habla más natural y, al mismo tiempo, supone otras transgresiones de tabúes porque con la hermana muerta, en este espacio secreto, no hace falta disfrazarse ni obedecer las reglas convencionales de la sociedad. Es el espacio que le pertenece a ella misma íntegramente, con sus subjetividades, inseguridades, locuras, miedos y, en suma, individualidades, que son solo suyas y de nadie más, dado que se desarrollan oralmente a través de un diálogo/monólogo con una chica muerta; son palabras que se pierden en el momento de ser pronunciadas.

\section{Conclusión}

La familia de la novela es como un microcosmos del país que reproduce los poderes y jerarquías sociales, en los que impera un clima general de normalización del abuso y la violencia. En lugar de proteger a los más vulnerables, el hogar deviene una cárcel en la cual se excluye, acalla y tortura a las mujeres. Alcira y Eni se configuran como dos perfiles que corren al borde del mismo abismo, es decir, representan a aquellas mujeres que sobreviven bajo el poder patriarcal y dictatorial; son supervivientes de la violencia estatal; son unas representantes de la Nación Argentina. 
Desde Norteamérica a Argentina, Alcira "corre" hacia el pasado para encontrar la verdad. El último pasaje de la novela es una carta para Eni escrita por Alcira en la que dice así:

Cuando me cortaste el teléfono la última vez, y porque mientras hablabas me parecía estar empezando a entender tus razones, sentí que todas las puertas que acababan de cerrarse ante mí con tu decisión me dejaban tan a oscuras que, en respuesta, se encendía la luz que, desde los recovecos de mis vísceras, me permitía hacerme cargo de mi propia historia (Kozameh, 2013: 311).

La búsqueda de Alcira del pasado en su país natal supone una indagación de la identidad de ella misma. El descubrimiento de la verdad sobre Eni y su vida, abre una puerta para Alcira a su propia historia. La conversación con la amiga de la infancia es una posibilidad para interpretarse a sí misma. Por fin, Alcira logra comprender la actitud de rechazo y repugnancia de Eni y comienza a reconstruir su propio espacio de la memoria. Vuelve a reinterpretar todo aquello que vivió de pequeña.

El desplazamiento de Laboulaye a Pergamino resulta ser indispensable para el comienzo de la tragedia de Eni. Alicia Kozameh, mediante distintas estrategias literarias, consigue exponer los hechos sucedidos en distintos momentos del pasado para destapar los recuerdos traumáticos de la protagonista y evidenciar que estos penetran en su presente. La movilidad espacial y temporal configura un panorama de los sufrimientos y las resistencias de dos mujeres de distintas clases a lo largo de casi toda su vida.

¿Te liberaste de tu circunstancia? Eni Furtado no ha dejado de correr para ser más feliz. Ha conseguido un espacio propio que le permite escribir tranquilamente todo lo que pasó, en tanto que ha construido un espacio mental, secreto y literario, o sea, un santuario de una subjetividad autónoma con sus reflexiones dispersas y pedazos fragmentarios. Alcira, por su parte, no ha dejado de luchar por la libertad. Es cierto que siempre pueden presentarse más complicaciones en la vida a medida que transcurre el tiempo, pero "la única independencia sucede en la constante lucha por lograrla".

\section{Referencias Bibliográficas}

DURÁN, María A. Semilla. "Del derecho a la militancia al derecho de las minorías: las nuevas perspectivas de los derechos humanos en la obra de Alicia Kozameh (Pasos bajo el agua, Ofrenda de propia piel, Eni Furtado no ha dejado de correr)". En Donde no habite el olvido: Herencia y transmisión de testimonio en Argentina, Emilia Perassi y Giuliana Calabrese (eds.), 213-226. Milano: Ledizioni, 2018.

FORCINITO, Ana. "Narración y escucha: Eni Furtado no ha dejado de correr". En Hasta el hueso. Nuevos asedios a la literatura de Alicia Kozameh, María A. Semilla Durán (ed.), 56-71. Ohio: Alternativas, 2019.

GALLARDO, Laura. "Un lugar extranjero llamado no-lugar: una reflexión sobre la necesidad del lugar y el no-lugar arquitectónico". Revista de Arquitectura, 18, 25 (2012): 10-15. 
GIRALDI, Norah. "Eni Furtado no ha dejado de correr: las heridas que la literatura revela". En Hasta el hueso. Nuevos asedios a la literatura de Alicia Kozameh, María A. Semilla Durán (ed.), 18-55. Ohio: Alternativas, 2019.

HERMAN, Judith. Trauma y recuperación: cómo superar las consecuencias de la violencia. Madrid: Editorial Espasa Calpe, 2004.

KOZAMEH, Alicia. Eni Furtado no ha dejado de correr. Córdoba: Alción, 2013.

KOZAMEH, Alicia. "Escribir es un drenaje doloroso". En Exiliadas, emigrantes, viajeras: encuentros con diez escritoras latinoamericanas, Erna Pfeiffer (ed.), 89-108. Madrid: Vervuert, 1995.

KOZAMEH, Alicia. "Falta y abismo: progenitores del compromiso". En Escritoras y compromiso: literatura española e hispanoamericana de los siglos $X X$ y $X X I$, Ángeles Encinar y Carmen Valcárcel (eds.), 41-56. Madrid: Visor, 2009.

KOZAMEH, Alicia. "No hay pasado. Y otras convicciones". Hispanic Issues OnLine, 22 (2019): 257-262.

KOZAMEH, Alicia. Patas de avestruz. Córdoba: Alción, 2003.

LORENZ, Federico (ed.). Pensar la dictadura, terrorismo de Estado en Argentina: preguntas, respuestas y propuestas para su enseñanza. Buenos Aires: Ministerio de Educación de la Nación Argentina, 2010.

NOUSELOVICI (NOUSS), Alexis. "Non-lieux (une atypologie)". Glossaire des mobilités culturelles, 8 (2014): 257-274.

PFEIFFER, Erna. "Vos, o yo, o las dos: formas de comunicación y estrategias informativas en Eni Furtado no ha dejado de correr". En Hasta el hueso. Nuevos asedios a la literatura de Alicia Kozameh, María A. Semilla Durán (ed.), 72-104. Ohio: Alternativas, 2019.

PFEIFFER, Erna. Alicia Kozameh: ética, estética, y las acrobacias da la palabra escrita. Pittsburgh: Inst. Internacional de Literatura Iberoamericana, 2013.

THIEBAUT, Carlos. "Mal, daño y justicia”. Azafea, 7 (2005): 15-46. 